\title{
A Tatuagem como linguagem artística na contemporaneidade
}

Francisco Benvenuto Gussol

Resumo: Com base na bibliografia analisada sobre interferências corporais e arte, estudou-se a relação da tatuagem com o campo da arte na contemporaneidade, partindo desde as primeiras manifestações da arte corporal pré-histórica até sua ocidentalização e modernização. São abordados introdutoriamente os motivos que levam as pessoas a adotarem a tatuagem como modificador corporal. Além de estudar artistas que se utilizam da linguagem da arte corporal como motivo para seus trabalhos, propomos uma reflexão sobre a tatuagem e suas possibilidades em diferentes suportes que vão além da pele. São eles: o ex tatuador Don Ed Hardy, a jovem artista escocesa Jessica Harrison e o paulistano Rafael Assef.

Palavras-chave: Arte Corporal; Tatuagem; Espaços expositivos; Corpo; Arte contemporânea.

\section{Introdução}

Há muito tempo a tatuagem esteve presente na sociedade, sendo reinventada várias vezes em diferentes momentos e partes da Terra, ela existiu em todos os continentes, com maior ou menor variação de propósitos, técnicas e resultados.

Os primeiros sinais encontrados das tatuagens são da era Paleolítica Superior, certa de 40.000 a 10.000 anos a.C. Foram encontradas evidências nas grutas de Lascaux, na França e também na Síria. Além de ferramentas utilizadas para a escarificação, descobriu-se

${ }^{1}$ Graduado em Desenho Industrial pela PUC-PR, estudante de gravura pela Escola de Música e Belas Artes do Paraná, bolsista no programa de iniciação científica pela UNESPAR 
que as pessoas daquela época adornavam os corpos com pó de ocre e corante mineral. Acredita-se que sua função era a princípio a comunicação com o sobrenatural e a comprovação da virilidade. Seriam originalmente manifestações de rituais religiosos, uma busca da magia através do sacrifício (rituais que envolviam sangue), busca de proteção, iniciação da puberdade ou preparo psicológico para guerra. (MARQUES, 1997 p. 23)

Com o tempo seu significado foi se modificando, acompanhando as evoluções da sociedade. Já na Idade Média, a tatuagem era considerada um misto de bandeira, atestado de nascimento, carteira de identidade, certificado de alistamento militar, medalha de honra ao mérito, vestimenta, aliança de casamento, joia, amuleto, superstição, remédio, sinal de luto ou biografia. (MARQUES, 1997 p. 40)
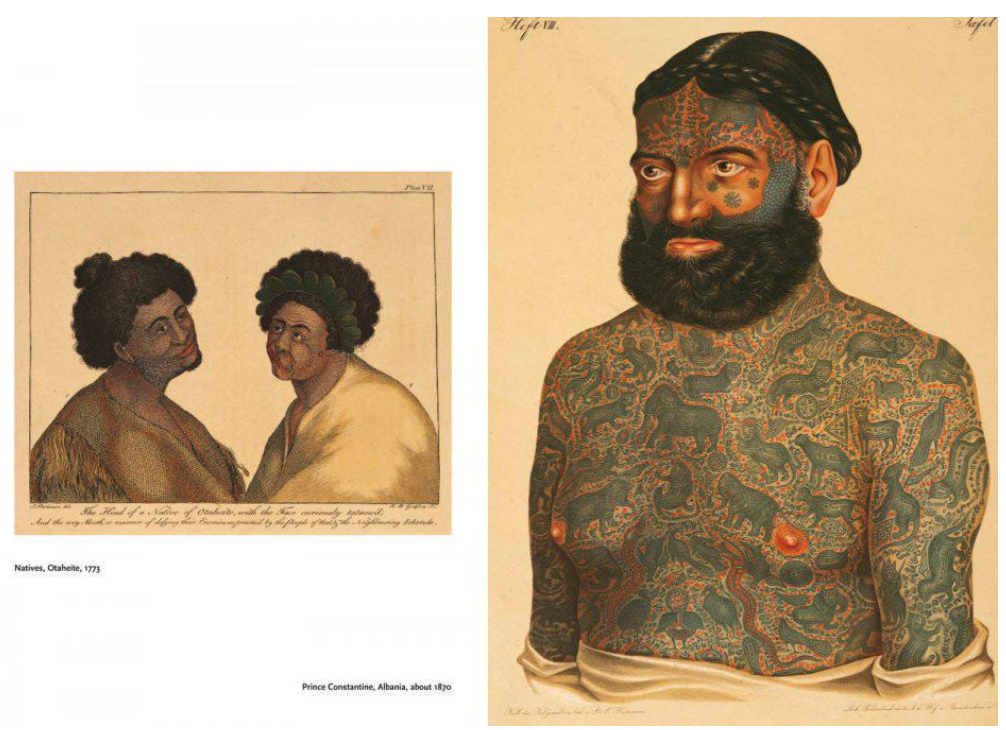

Figura 1: esq. Nativos, Otaheite,1773. dir. Príncipe Constantine, Albania, cerca de 1870. (SCHIFFMACHER, 2000 p. 30) 
Pode-se dizer que a tatuagem moderna teve seu início através da exploração europeia, com a conversão dos europeus ao costume de se tatuar e a entrada dos temas "brancos" nos desenhos, o que quase extinguiu a tradicional tatuagem tribal ao redor do mundo. A Europa e os Estados Unidos desmantelaram culturas tatuadas e no final do século XX passaram a lhes vender a tatuagem ocidental. (MARQUES, 1997 p. 45)

Tanto na Europa como nos Estados Unidos a tatuagem entrou pelo mar, se popularizou entre as classes mais baixas no século XIX e virou um fenômeno de massa durante a Guerra Civil. Na primeira década, era comum encontrar um tatuador a bordo de um navio da Marinha Americana. A moda entre os marinheiros era tão grande que em 1909 uma lei procurou regulamentar a prática da tatuagem. $\mathrm{O}$ documento proibia qualquer pessoa que possuísse tatuagens obscenas e indecentes de se alistar, sendo motivo para rejeição à candidatura ao regimento. $\mathrm{Na}$ década de 20, em quase toda a América do Norte se tornou proibido que menores de idade fossem tatuados, mais tarde, os maiores de idade também. A proibição se deu por razões de saúde pública, com o intuito de conter a proliferação da hepatite e da sífilis. Assim, a tatuagem se tornou algo fora da lei, sendo com frequência associada a pessoas apartadas do resto do mundo. Na França no início do século XX as tatuagens compunham o visual de delinquentes juvenis e membros de gangs. Era o símbolo de seus espíritos desordeiros. Tatuavam o nome das amantes, além de sinais de reconhecimento e frases antissociais como 
"viva a anarquia! Morte aos tiras" ou "A prisão será o meu túmulo". (MARQUES, 1997 p. 64)

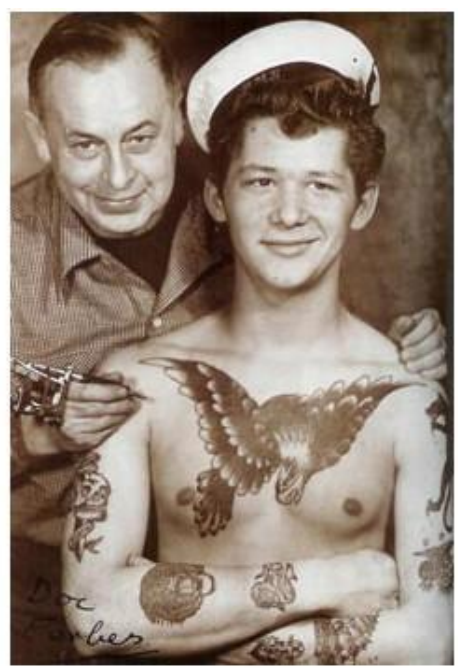

Figura 2: Marinheiro americano tatuado pelo artista Doc Forbes, Vancouver, Canadá, 1957. (SCHIFFMACHER, 2000 p. 208)

Atualmente a tatuagem possui uma função principalmente estética e vive momentos de glória. Passou por uma notável ascensão social e o mercado primeiro-mundista se sofisticou tanto que determinados tatuadores se livraram da obrigação de atender a todo tipo de pedidos, tendo total liberdade para desenvolver seu próprio estilo, garantindo um público fiel à sua arte. Um dos maiores exemplos é Sailor Jerry Collins (1911-1973), ex-marinheiro, cujas tatuagens fundiram os estilos da tatuagem oriental com as tradicionais tatuagens clássicas americanas. Tornou-se até hoje um dos maiores representantes da tatuagem moderna. 


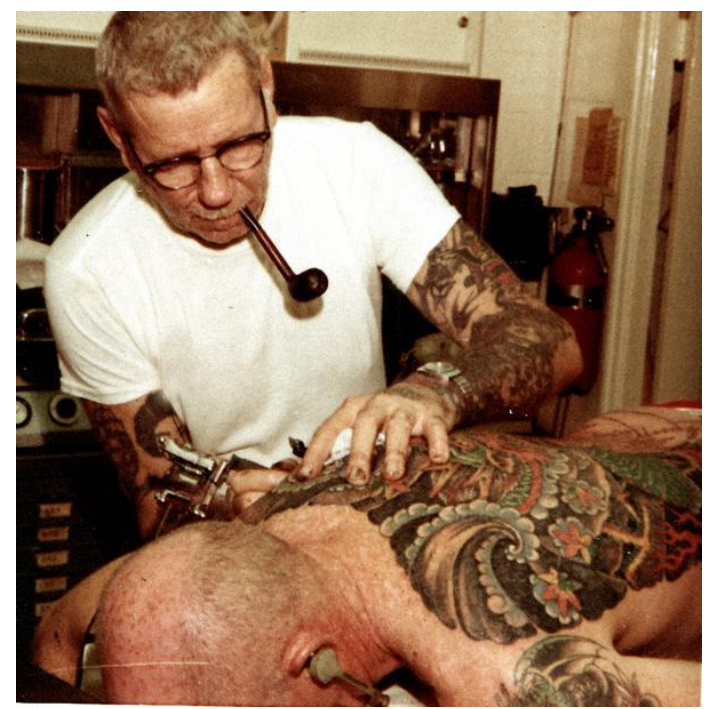

Figura 3: Sailor Jerry Collins tatuando no Japão, década de 70.

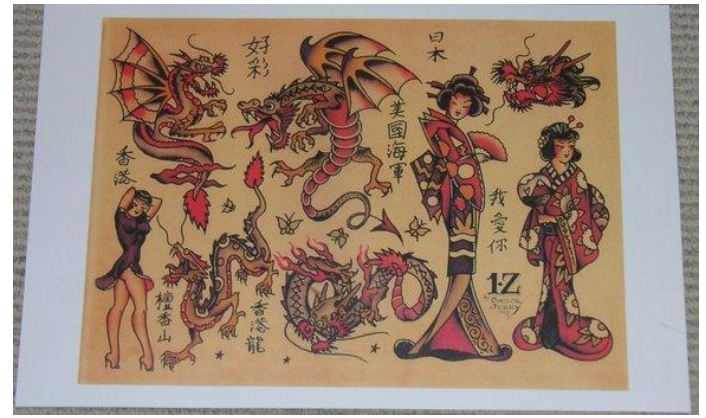

Figura 4: Pintura de Sailor Jerry, mistura de temas orientais com estilo americano.

Tendo em vista o estágio atual pelo qual passa a tatuagem, que pode ser visto de forma bem resumida até este momento do texto, focaremos agora na importante relação entre as artes visuais eruditas e a tatuagem. 


\section{A era moderna}

Observa-se que a história da tatuagem moderna é muito recente. Segundo explica Toni Marques, em seu livro "O Brasil tatuado e outros mundos", a primeira convenção internacional de tatuagem aconteceu em 1976, no Texas. Com o sucesso da primeira edição, mais uma aconteceu no ano seguinte no Estado de Nevada. Lá, novas técnicas, diferentes das tradicionais norte-americanas, começaram a ser divulgadas, como a técnica do pontilhismo, a primeira grande influência pós-Japão na tatuagem americana e mundial. A partir dali as referências não pararam de crescer e a criação não teve mais barreira. Buscou-se inspiração desde Michelangelo, Da Vinci, Van Gogh, Mondrian, Miró e Picasso até no cinema, nos quadrinhos, desenhos animados e cultura Pop em geral. (MARQUES, 1997 p. 73)

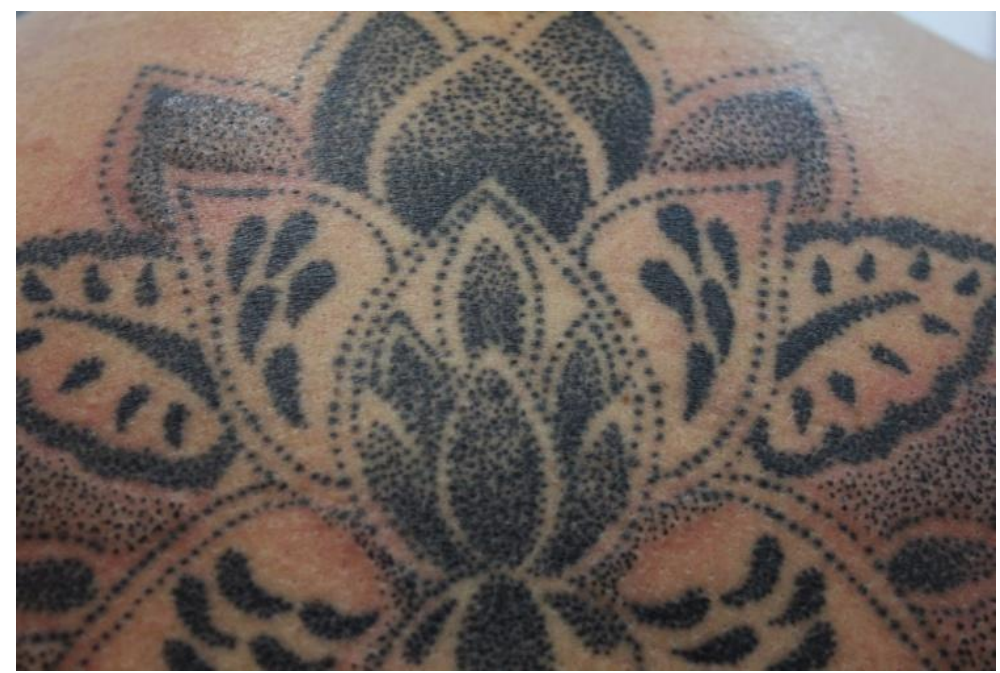

Figura 5: Exemplo de tatuagem pontilhista. 


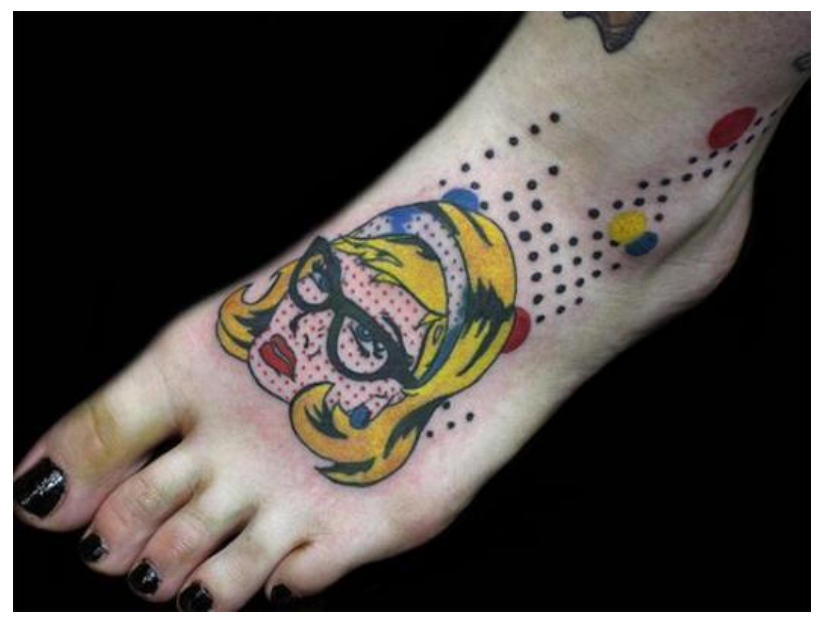

Figura 6: exemplo de diferentes estilos, tatuagem inspirada na arte pop de Roy Lichtenstein.

Com a sofisticação e popularidade em alta, as tattoos se espalharam pelos museus em San Francisco e Amsterdam. Exposições importantes como a do Museum of Folk Art de Nova York em 1972, foram criadas com o objetivo de libertar a tatuagem de seu estigma undergound. Outra exposição importante foi a "Tatouages" de 1977, que aconteceu no Centro Georges Pompidou em Paris. Esta repercutiu na imprensa internacional, o que comprovava o crédito conquistado pela alta cultura. Com a evolução das técnicas e tecnologia abriu-se caminho para uma nova revolução, libertando a tatuagem cada vez mais dos costumes antigos e expandindo sua cultura por todos os cantos. Atualmente a estética da tatuagem marca não só a pele, mas também outros suportes como telas, paredes, roupas, carros e salas dos museus. (MARQUES, 1997 p. 65). 

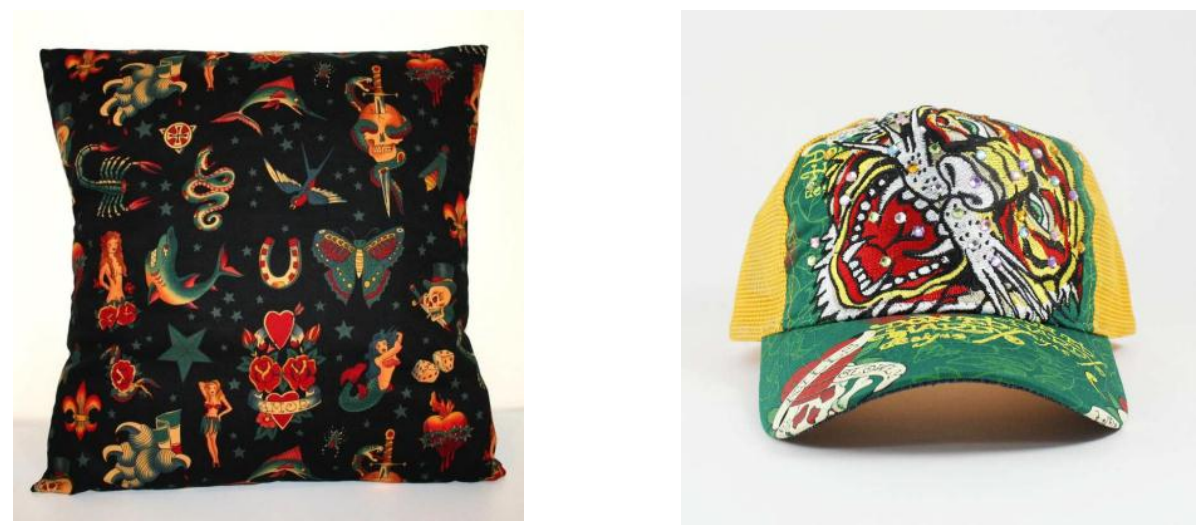

Figura 7: desenhos tradicionais de tatuagens aplicados em diferentes suportes além da pele.

\section{Porque as pessoas se tatuam?}

À primeira vista, pode-se dizer que todas as pessoas se tatuam por vaidade. Porém, muita coisa existe por traz do ato de pigmentar permanentemente a pele. Para a pesquisadora Beatriz Ferreira Pirez, a tatuagem além de marca estética possui o caráter de amuleto protetor.

A tatuagem hoje, representa um prolongamento da mente. $\mathrm{O}$ indivíduo que a adquire transfere para ela a memória de um fato ou de uma situação. A lembrança que antes habitava na memória ou em determinados objetos externos ao corpo, agora é incrustada na pele. (FERREIRA, 2005 p. 106)

Segundo o body artist e pesquisador Fakir Musafar "Tudo se resume a este princípio: o corpo é seu, joga com ele! Vejo que as pessoas têm uma necessidade desesperada destes ritos, eis porque renascem o piercing e a tatuagem. De um modo ou de outro, as pessoas precisam de 
uma cultura tribal" (MUSAFAR, apud V. Vale \& A. Juno, Tatuaggi, corpo, spirito).

Partindo de um ponto de vista mais filosófico, toda alteração corporal parece ser resultante de um desejo proveniente de uma memória ancestral. De um modo ou de outro, as pessoas em geral têm uma necessidade natural de uma cultura tribal. As marcas feitas sobre o corpo resgatam conhecimentos primordiais, estabelecendo uma relação tátil e visível entre o indivíduo e o cosmos. As marcas corporais adquiridas podem ser vistas como uma forma que a pessoa marcada encontra para conectar-se ao universo. $\mathrm{O}$ ato de depositar pigmento por baixo da pele permite a pessoa que se tatua incorporar a abstração à sua pele e dá a essa região uma marca que possui a característica definitiva de não se transformar, de algo que não vai sumir nunca mais. Assim, a ferida aplicada à pele proporciona ao seu portador a sensação de imortalidade. (FERREIRA, 2005 p. 101)

Podemos também, entender a pele como uma intermediadora de espaços interno e externo ao corpo, comparando-a aos sonhos, que são mediadores entre o estado inconsciente e o consciente da mente. Algo que fascina em relação aos corpos tatuados é a postura e a coragem que as pessoas adeptas a este costume tem de jogar, experimentar e vivenciar o inconsciente.

As imagens das tatuagens são histórias contadas. Elas são um tipo de iconografia, como um símbolo que representa, de algum modo, uma pequena história. Como se os desenhos clássicos tivessem uma lenda por traz. Desde o início da tatuagem tradicional americana até os dias de 
hoje, os desenhos clássicos foram reproduzidos tantas vezes, em tão diversos contextos, que foram aos poucos perdendo seu sentido original, mudando para algo adaptável aos gostos de quem simpatizava com determinado desenho, ganhando assim uma nova significação.

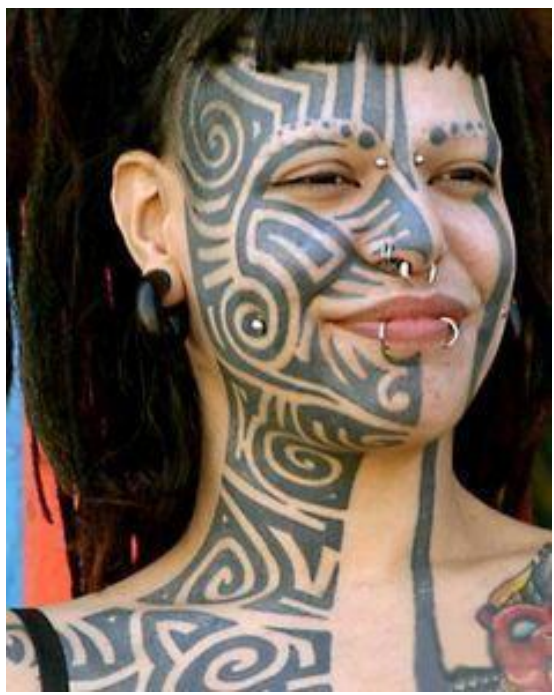

Figura 8: Exemplo de modern primitive, fonte desconhecida. (Modern primitive é a pessoa que se dedica à rituais e práticas de modificação corporal ao fazer referência ou homenagem aos ritos de passagem praticadas em "culturas primitivas". A motivação para se envolver nestas práticas variadas pode ser o crescimento pessoal, ritual de passagem, ou curiosidade espiritual ou sexual.)

\section{A tatuagem como linguagem artística na contemporaneidade.}

É comum associarmos tatuagem e arte, porém esta associação é algo complicado, dependendo do conceito e da definição atribuída à arte. Sem dúvidas, o tatuador é um artesão. Mas seu trabalho pode ser comparado ao de um pintor ou de um escultor? Seus desenhos reproduzidos sobre a pele são resultados de uma visão de mundo e reflexão sobre a vida? 
A tatuagem é como uma biografia encomendada, o biógrafo cria uma forma escrita para a vida do biografado, comunicando a perícia do tatuador e o imaginário do tatuado. O grande problema da tatuagem é que ela não resiste ao tempo, não resiste à morte. A obra original já nasce condenada a desaparecer junto com quem a possui. Ela precisa do desenho, da fotografia, do cinema, do computador, das letras e obviamente da arte para continuar a existir - ou seja, do registro. (MARQUES, 1997 p. 238)

Ao dar-se conta da complexidade existente por trás da tatuagem e sua relação com seus portadores, buscamos nos aprofundar sobre o artista que reproduz o ato de tatuar e assume a grande responsabilidade de eternizar determinado símbolo na vida de alguém. Nas civilizações antigas, a função de marcar as pessoas era reservada a figuras religiosas. Hoje o posto é formado na grande maioria por pessoas provenientes da classe média, roqueiros, rappers, ilustradores, grafiteiros, designers e artistas plásticos. De uma forma ou de outra, todos têm uma ligação com as artes visuais. É notável o crescimento de tatuadores que ingressaram nas academias de belas artes nos últimos cinco anos. Praticamente todas as turmas dos cursos de Artes Visuais nas universidades públicas do Paraná, por exemplo, possuem ao menos um aluno que pratica a tatuagem. Da mesma forma, é crescente o número de artistas plásticos já consolidados que buscam na tatuagem uma nova possibilidade de linguagem.

Antes era a pele que servia de suporte para a arte corporal, hoje ela se expande para qualquer outro corpo que se possa acrescentar vida e 
um caráter artístico. Alguns tatuadores direcionam a arte de tatuar para além do seu suporte natural propondo um diálogo entre sua arte e as galerias de arte. A exposição "A pele é a parede", que ocorreu em Londrina em 2011 contou com o trabalho de 15 tatuadores e é um caso exemplar. A ideia da exposição era transformar o espaço expositivo em um corpo, onde os artistas pudessem tatuar. Segundo os próprios tatuadores que participaram da exposição, o resultado foi a construção de um novo pensamento a respeito do corpo metafórico e a arte de se deixar marcar.

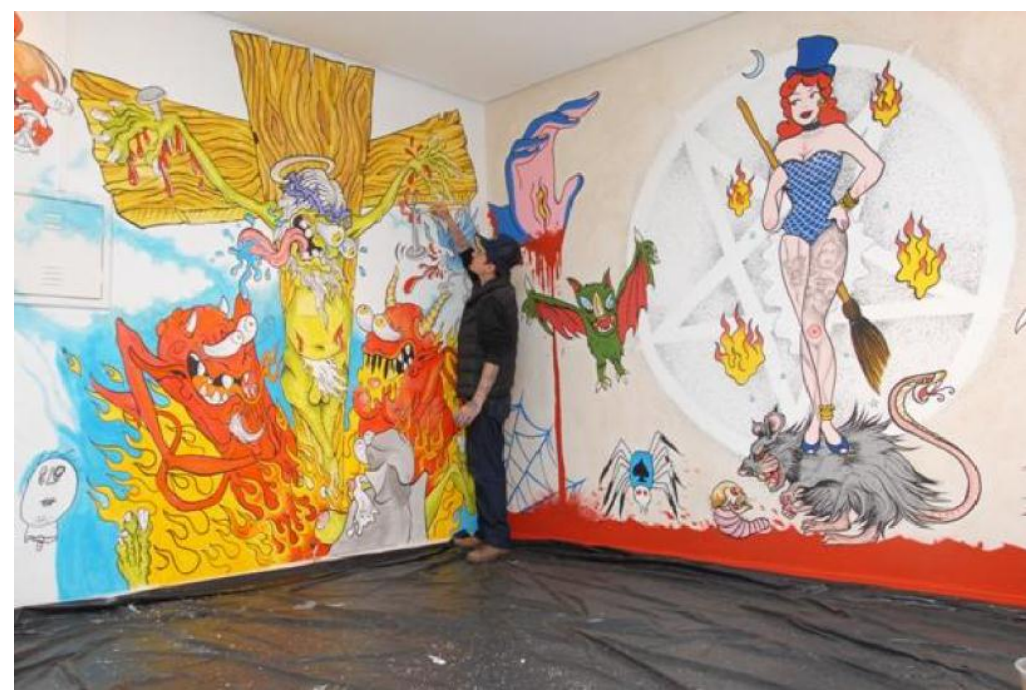

Figura 9: Exposição “A Parede é a Pele”, Londrina, 2011.

A seguir, apresentaremos alguns artistas contemporâneos que se inspiram na tatuagem para sua produção artística. $O$ primeiro a mencionarmos é Don Ed Hardy. Ele é considerado um dos maiores promotores culturais da tatuagem contemporânea. Nasceu na Califórnia 
em 1945, e passou a infância determinado a se tornar tatuador. Começou a trabalhar como aprendiz enquanto cursava a Universidade de Gravura no San Francisco Art Institute em 1967. Logo passou a trabalhar profissionalmente com tatuagem. Viveu no Japão durante os anos 70, onde aprendeu as técnicas da tatuagem oriental com verdadeiros mestres locais, misturando o estilo japonês com a tradicional tatuagem norteamericana. A partir dos anos 80 , começou a se dedicar principalmente a sua produção artística, incluindo desenhos, pinturas, gravuras e porcelanas. Continua participando de inúmeras exposições até os dias de hoje. Seu trabalho se popularizou tanto que saiu das galerias e virou marca para roupas e grife de estilistas famosos. $\mathrm{O}$ artista comenta sobre o seu próprio trabalho:

Vai além de nós mesmos e nossas intenções conscientes e muda-se para uma região do que poderíamos chamar de arte. É uma sorte ser capaz de manobrar nessa esfera, e eu tenho mantido o objetivo nessa área, tentando ativar as coisas. Tatuagem é o meio que me permitiu fazer isso." (http://www.hardymarks.com) ${ }^{1}$

Para ele, é absurda a ideia de que a arte da tatuagem se limite apenas a fins estéticos. $\mathrm{O}$ mundo da tattoo se expandiu para uma forma

${ }^{1}$ (Tradução nossa) It takes us beyond ourselves and our conscious intentions and moves into the realm of what you could call art. It's fortunate to be able to maneuver in that realm, and I've kept aiming at that, trying to activate things. Tattooing is the medium that allowed me to do that. 
visual inimaginável espalhando-se por todos os lugares. Hoje Ed Hardy parou de tatuar e se dedica exclusivamente às Artes Plásticas.

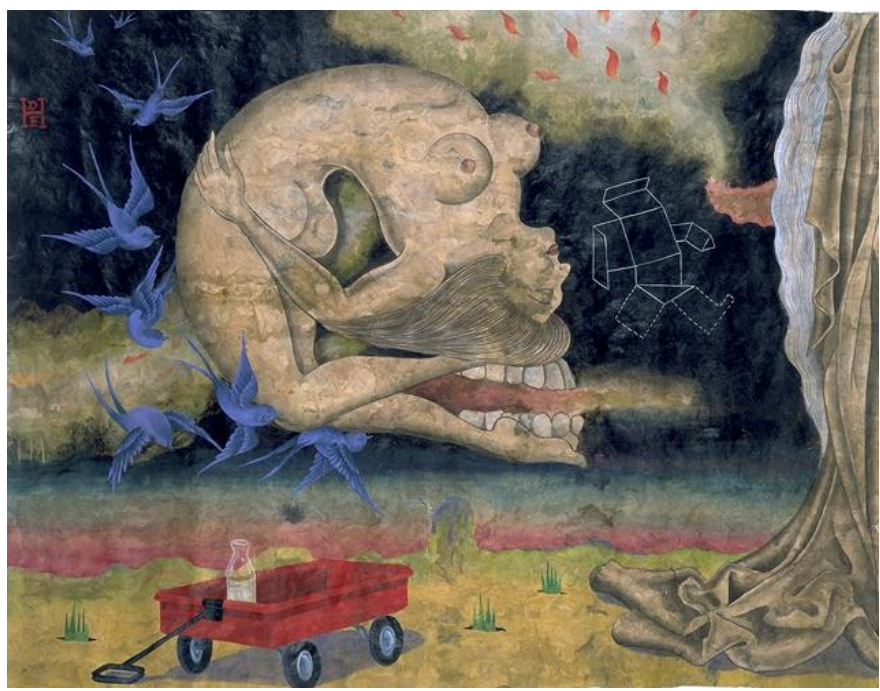

Figura 10: pintura de Don Ed Hardy, 1980. 


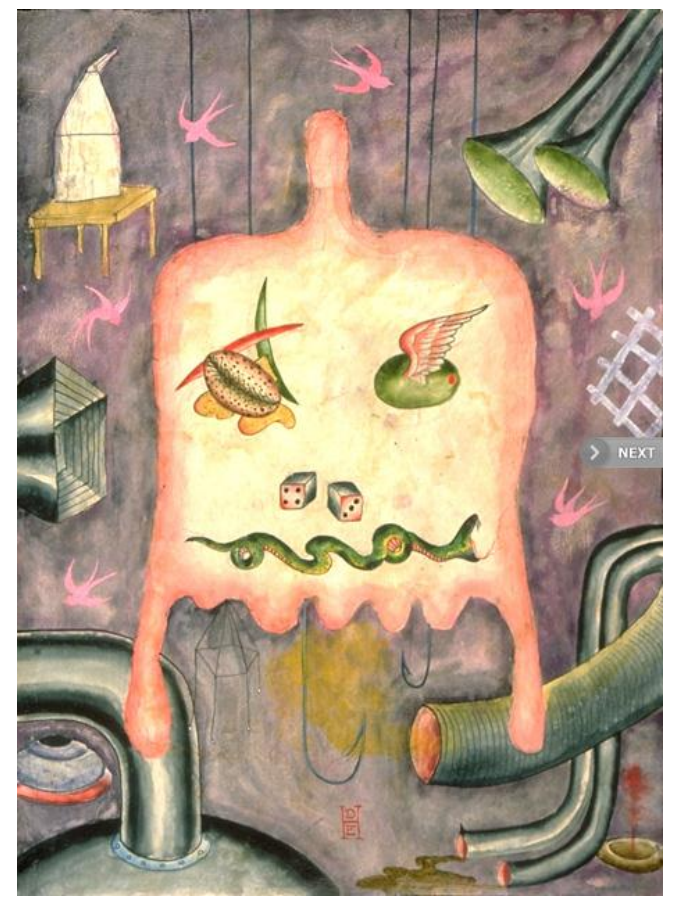

Figura 11: pintura de Don Ed Hardy, 1980.

Outra artista que se destaca é a escocesa Jessica Harrison, que tem uma produção bem recente. Nasceu em St Bees em 1982 e se mudou para a Escócia em 2000 para estudar escultura na Escola de Artes de Edinburgh, seguido por um Mestrado em Artes (MFA) antes de completar um PHD prático (practice-led PHD) em Escultura em 2013, patrocinada pelo Concil de Pesquisa em Artes e Humanas (Arts and Humanities Research Council).

Sua pesquisa considera a relação entre os espaços interior e exterior do corpo, mas não foca no núcleo escondido no subconsciente. Ao contrário, foca perpendicularmente da pele para o movimento do 
próprio corpo. Ela constrói esculturas de porcelana que representam a figura humana e as tatua.

Harrison propõe um modelo multidirecional e penetrante da pele como um espaço onde o corpo e o mundo se misturam. Trabalhando com este espaço em movimento entre o artista/criador e espectador, ela desenha sobre o corpo ativo de ambos.

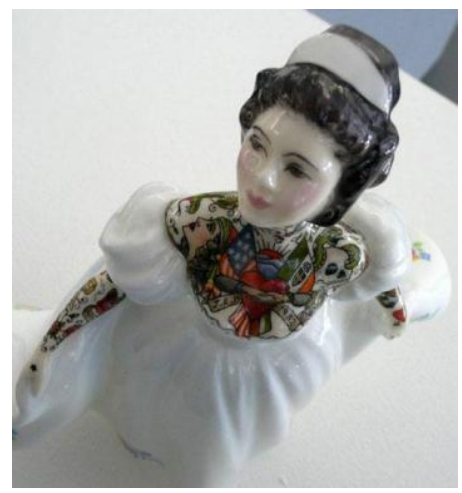

Figura 12: obras da série Painted Lady de Jessica Harrison, 2013, cerâmica, esmalte cerâmico.

Outro artista a trabalhar com o corpo, mais especificamente, a tatuagem como linguagem na arte contemporânea é o fotógrafo paulistano Rafael Assef. Em seus trabalhos a pele funciona como uma tela na qual são feitas incisões. A sensação de dor que transparece ao ver seu trabalho é imediata. Ao ativar experiências dolorosas, Assef provoca no espectador o incômodo diante de ações contra o próprio corpo. Em sua série "Traço", de 1999, os desenhos tornam-se vestígios produzidos sem pigmentação e, sim, com sangue. A radicalidade presente nas incisões de Rafael Assef pode ser encontrada também em performances de artistas internacionais da década de 1970, como Otto Muehl, Hermann Nitsch, 
Gina Pane, Günter Brus, Michel Journiac, entre outros, em que o corpo se torna suporte para ações extremas. Mas, ao contrário dessa geração, os trabalhos fotográficos de Assef não são apenas registros de performances, simples testemunhos imagéticos. Suas tatuagens e escarificações são fotografadas, e são essas fotografias que são exibidas. $\mathrm{O}$ importante em seu trabalho é o resultado visual que vai além da performance. (Enciclopédia ITAÚ CULTURAL DE ARTES VISUAIS, Rafael Assef)

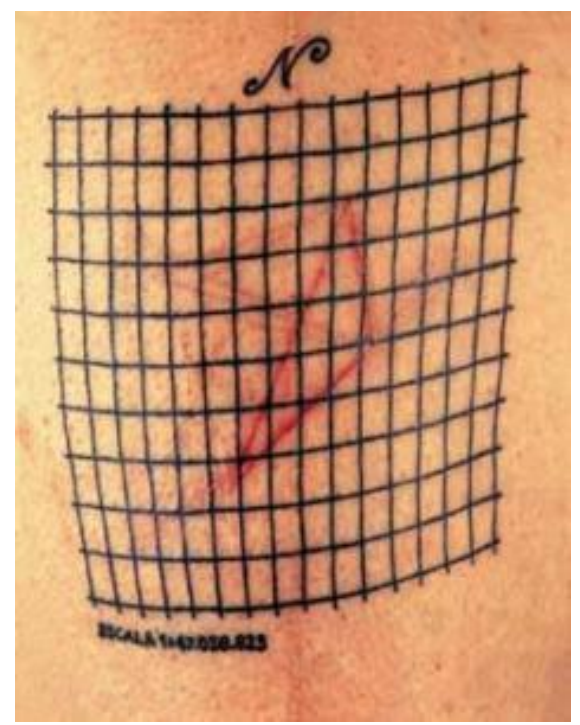

Figura 13: Cartografia aos 27 anos, da série Atlas, Rafael Assef 


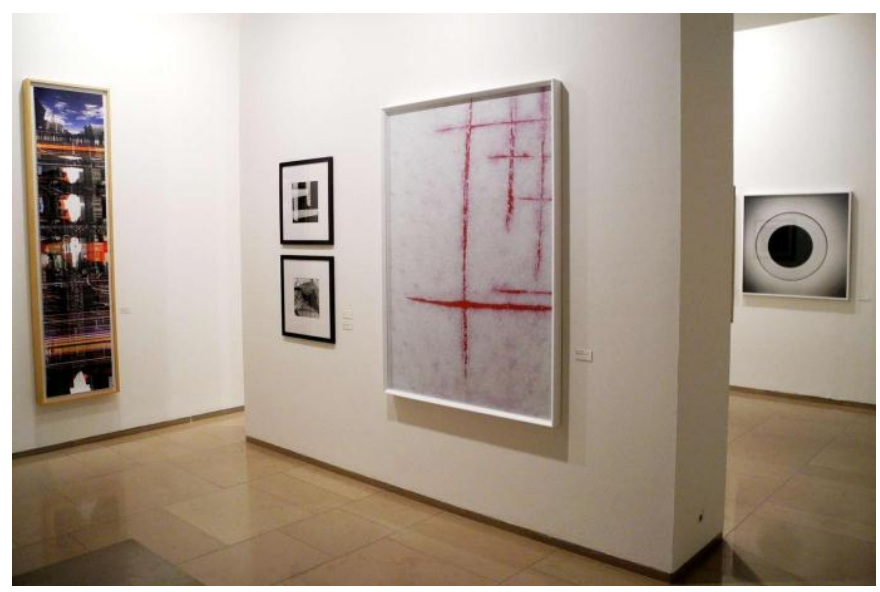

Figura 14: Matemática Áurea, Rafael Assef, 2000.

\section{Conclusão}

Após analisar a bibliografia selecionada e se aprofundar no universo da tatuagem e da arte de gravar, pode-se verificar com mais clareza a importância da tatuagem como linguagem artística e sua intensa ligação com o universo humano. Foram comentadas algumas das razões pelas quais as pessoas tatuam seus corpos e como, às vezes, usam a tatuagem como tema para sua criação artística. Também se apresentou brevemente alguns artistas visuais contemporâneos cujo trabalho artístico em galerias e demais espaços expositivos dialogam ou incorporam a tatuagem. São eles: Don Ed Hardy, Jessica Harrison e o paulistano Rafael Assef. Destes três, apenas um era tatuador.

A principal função da tatuagem é gravar. Ela carrega em si o desejo de conservar algo na memória. Ao expandir para outras superfícies, a arte de tatuar revela o que marca, o que fere, o que é inapagável. É importante não limitarmos a tatuagem apenas a fins 
estéticos. No mundo todo, a tatuagem se expandiu para uma forma visual inimaginável espalhando-se por todos os cantos. Cada vez mais artistas se encontram dentro deste universo, buscando na tatuagem maior motivação para sua criação, exibindo seus trabalhos dentro e fora dos museus. Hoje, com a quantidade de referências visuais que encontramos na internet e a evolução das técnicas, as possibilidades artísticas de criação se tornaram infinitas, estimulando a ideia de que a tattoo é sem dúvida uma manifestação artística sem limites, indo além da pele para qualquer suporte existente, portanto, legítima.

\section{Referências}

\section{Livros}

COSTA, Alex. Tatuagens de A a Z. Ad Santos, 2011.

MARQUES, Toni. O Brasil tatuado e outros mundos. Rocco, 1997.

NETO, Meton de Alencar; NAVA, José. Tatuagens e desenhos cicatriciais. MP, 1966.

SHELLEY, Mery. Frankenstein. Martin Claret, 2012.

SCHIFFMACHER, Ed Henk. 1000 Tattoos. Taschen, 2012.

\section{Artigos}

CRUZ, Joana Losada. A tatuagem e suas representações: uma reflexão sobre a arte corporal e o uso de outros suportes. Artigo.

RIO, João do. Os tatuadores. Revista Kosmos, 1904.

KIST, Cristine. $\mathbf{1}^{\mathbf{0}}$. Censo de tatuagem do Brasil. Revista Super Interessante, ed. 330, 2014. 
PIANOWSKI, Fabiane. O corpo como arte; Gunter Brus e o acionismo vienense. Teoria y critica del arte, Universidad de Barcelona.

VIANNA, Alexander Martins. O novo moderno prometeu: o espelho de Victor Frankenstein. IN: Revista Espaço Acadêmico - Ano III - n. ${ }^{\circ} 26$ julho de 2003. Disponível em http://www.espacoacademico.com.br/026/26cvianna.htm

\section{Artigos de internet}

Enciclopédia Itaú Cultural de Artes Visuais. Rafael Assef. IN: http://www.itaucultural.org.br/aplicexternas/enciclopedia_IC/index.cfm ?fuseaction $=$ artistas_biografia\&cd_verbete $=3087 \& c d \_i d i o m a=28555 \& \mathrm{c}$ d_item=1. Acesso em 17 jul. 2014.

Jessica Harrison IN: http://www.jessicaharrison.co.uk/. Acesso em 17 jul. 2014.

Hardy marks publications , Don Ed hardy IN: http://www.hardymarks.com/. Acesso em 17 jul. 2014. 